\title{
SABERES E FAZERES: 0 ESTÁGIO E SUAS CONTRIBUIÇÕES NO CURSO DE PEDAGOGIA
}

\author{
KNOWLEDGE AND PRACTICES: THE STUDENT TEACHING AND ITS \\ CONTRIBUTIONS FOR THE PEDAGOGY MAJOR
}

\section{SABERES Y HACERES: LA PASANTÍA Y SUS CONTRIBUCIONES EN EL CURSO DE PEDAGOGÍA}

\author{
Célia Aparecida Bettiol ${ }^{\star}$ \\ Adria Simone Duarte Souza* \\ Yoshie Ussami Ferrari Leite ${ }^{*+*}$
}

\begin{abstract}
Resumo: Este trabalho apresenta os resultados de um estudo realizado na Universidade do Estado do Amazonas com o objetivo de analisar a organização do estágio no curso de Pedagogia e verificar como as atividades de estágio são vivenciadas pelos alunos. Os envolvidos foram alunos que cursaram a disciplina de Estágio I, II e III que responderam a questionários, fizeram produções de textos e participaram de discussões grupais. Fizemos também uma análise do Projeto 'Político Pedagógico do curso. Os resultados do trabalho demonstram que a concepção do professor reflexivo embasa a proposta de estágio no curso de Pedagogia da Universidade do Estado do Amazonas e isso é considerado algo positivo pelos alunos, assim como vincular o estágio à pesquisa foi igualmente considerado importante para a sua formação. O plano de ação docente, atividade proposta na ementa da disciplina, foi considerado como um dos pontos mais relevantes do estágio. O momento de elaboração do trabalho evidenciou que o planejamento é encarado de forma significativa pelos acadêmicos como algo necessário, e a sua realização trouxe à tona algumas fragilidades na formação recebida, como a insegurança diante das metodologias de ensino e a elaboração e uso dos diferentes instrumentos de avaliação. O registro da experiência se colocou como uma necessidade para possibilitar a reflexão sobre o vivido e oportunizar, a partir de sua retomada, a reflexão da prática docente a partir dela própria, pressuposto do professor reflexivo. No entanto, os resultados também apontam para a necessidade de repensar a organização da disciplina no currículo e um acompanhamento mais efetivo das atividades. Concluiu-se que o estágio é um espaço de formação reconhecido pelos acadêmicos como relevante, porém contém ainda limitações na organização do seu percurso, o que fragiliza o processo de formação docente.
\end{abstract}

Palavras-chave: Estágio. Formação docente. Curso de Pedagogia.

Abstract: This paper presents the results of a study at the Amazonas State University which aimed
analyse of the organization of the Student Teaching in the Pedagogy major and also in the verificti
of how it is experienced by the students. The students involved in this study have participat
the Student Teaching courses I, II and III, filled the questionnaires, produced a writing text and
participated of some discussions in group. A documental analysis of the educational project of
course was also done. The results of the study demonstrate that the conception of a reflexive te
Universidade do Estado do Amazonas - UEA. Email: celiabbettiol@gmail.com
Universidade do Estado do Amazonas - UEA. Email: adriasimone@bol.com.br
Universidade do Estado de São Paulo - UNESP - Campus Presidente Prudente. Email: yoshie@fct.unesp.br 
establish the purpose of the experience of the Student Teaching in the Pedagogy major of the Amazonas State University and it is well considered by the students. Associating the teaching experience to the research was also considered important for the training of the students. The Teacher Action Plan, an activity proposed in the Education major was considered as the main point of the student teaching experience. The time used to prepare the work evidenced that the planning seems to be important for the students and its realization has revealed some weaknesses in the teacher training as the lack of confidence on the teaching methodologies and the development and the use of different assessment tools. The registration of the experience was pointed as a need to enable reflection about it and create new opportunities from it, the reflection of the teaching practice itself and the assumption of a reflective teacher. However, the results also suggest the need for rethinking the organization of the course in the curriculum and a more effective monitoring of the activities. From our experience, it can be concluded that the importance of the student teaching as a space of training has been recognized by the scholars; however, some limitations still remain in the organization of its execution, which weakens the process of teacher education.

Keywords: Student Teaching. Teacher Training. Pedagogy major.

Resumen: El trabajo presenta los resultados de un estudio realizado en la Universidad del Estado de Amazonas con el objetivo de analizar la organización de la pasantía en el curso de Pedagogía y verificar cómo el mismo es experimentado por los alumnos. Los involucrados fueron alumnos que cursaron la asignatura de Pasantía I, II y III que respondieron a cuestionarios, hicieron producciones de textos y participaron de discusiones grupales. Hicimos también un análisis documental en el PPC del curso. Los resultados del trabajo demuestran que la concepción del profesor reflexivo embasa la propuesta de pasantía en el curso de Pedagogía de la Universidad del Estado de Amazonas y eso es considerado algo positivo por los alumnos. Vincular la pasantía a la pesquisa fue igualmente considerado importante para la formación de los mismos. El plan de acción docente, actividad propuesta en el resumen de la asignatura, fue considerado como uno de los puntos más relevantes de la pasantía. El momento de elaboración del trabajo evidenció que el planeamiento es visto de forma significativa por los académicos como algo necesario y su realización trajo algunas fragilidades en la formación recibida como la inseguridad delante de las metodologías de enseñanza y la elaboración y uso de los diferentes instrumentos de evaluación. El registro de la experiencia fue colocado como una necesidad para posibilitar la reflexión sobre lo vivido y dar oportunidad, a partir de su retomada, a la reflexión de la práctica docente a partir de la propia, presupuesto del profesor reflexivo. Sin embargo, los resultados también apuntan para la necesidad de repensar la organización de la asignatura en el currículo y un acompañamiento más efectivo de las actividades. De esta forma, concluimos que la pasantía es un espacio de formación reconocido por los académicos como relevante, pero, notamos aun limitaciones en la organización de su recorrido, fragilizando el proceso de formación docente.

Palabras-clave: Pasantía. Formación docente. Curso de Pedagogía.

\section{Introdução}

O aumento quantitativo de matrículas nas escolas públicas nas últimas décadas tem colocado em pauta diferentes problematizações sobre a educação nacional e, dentre elas, especificamente, tem-se discutido a formação de professores neste novo contexto. Nestas discussões, inúmeros debates têm sido abordados, e várias pesquisas têm mostrado que os profissionais não estão recebendo formação suficiente para enfrentar os desafios encontrados nas salas de aula e nas escolas. (Gatti e Nunes, 2008). Dentre os questionamentos 
levantados, tem merecido destaque o lugar que o estágio supervisionado e as práticas pedagógicas ocupam na aprendizagem de conteúdos necessários ao trabalho docente. Leite (2011) afirma que o professor precisa ser capaz de compreender o contexto social onde ocorre o ensino-aprendizagem, remetendo-se à realidade das escolas e dos problemas aí encontrados.

Este texto apresenta os resultados de um estudo sobre o Estágio Supervisionado na Universidade do Estado do Amazonas - UEA no curso de Pedagogia e cujos objetivos foram os seguintes: analisar o estágio no Curso de Pedagogia a partir dos relatos dos acadêmicos, conhecer as concepções teóricas e práticas da proposta de estágio estabelecida por essa universidade; identificar as dificuldades e aprendizagens dos alunos no percurso do estágio e verificar como a sua prática é avaliada por eles.

Entendemos que refletir sobre o estágio na formação dos professores é relevante na medida em que este processo é imprescindível para a construção da identidade docente.

\section{O Estágio nos cursos de licenciatura}

O componente curricular Estágio Supervisionado é compreendido como o espaço em que o aluno aprofunda e fortalece o processo de ação-reflexão-ação, revelando-se um momento de fundamental importância na formação do profissional em educação posto que permite a articulação entre conhecimentos teórico-práticos adquiridos ao longo do curso.

A experiência de estágio na formação de professores possibilita um contato real com a escola e seu cotidiano. Tal experiência oportuniza ao aluno realizar um trabalho de síntese entre teoria e prática educativa, algo que necessariamente implica a reflexão sobre as ações ali desenvolvidas e a construção de um significado para essas ações. Dessa forma, o processo formativo, ao mesmo tempo em que valoriza a prática docente como fonte de pesquisa e de autonomia do professor, dá ao educador/professor a responsabilidade por seu desenvolvimento profissional.

Segundo Pimenta (2008, p. 62), “a identidade do professor é construída ao longo de sua trajetória como profissional do magistério”. No entanto, é no processo de sua formação que são consolidadas as opções e intenções da profissão que o curso se propõe legitimar.

Pimenta e Ghedin (2002) concebem o professor reflexivo como o profissional que aprende a partir da análise e interpretação de sua própria atividade. Nesse sentido, concordamos com Leite (2011) quando afirma que “[...] no processo formativo do profissional docente, cabe ao estágio um papel fundamental na construção de sua identidade profissional, considerado, portanto, espaço privilegiado para a formação do docente, na perspectiva da concepção do professor crítico-reflexivo”. (p.43)

O estágio como campo de conhecimento e eixo central nos cursos de formação de professores possibilita que seja trabalhado com os acadêmicos aspectos indispensáveis à construção da identidade e dos saberes específicos dos professores. (PIMENTA, 2008).

\section{Percurso metodológico do trabalho}

As informações aqui discutidas são resultado do trabalho com uma turma de trinta e três alunos do curso de Pedagogia que frequentaram a disciplina Estágio Supervisionado I, II e III. Segundo o Projeto Político Pedagógico do Curso de Pedagogia da Universidade do Estado do Amazonas (UEA), 
Concebe-se estágio como a experiência profissional na qual se busca articular e construir saberes, a partir da prática docente, da participação na gestão de processos educativos e da atividade de pesquisa, em escolas da rede pública e particular de ensino, preferencialmente da educação infantil e dos anos iniciais do Ensino Fundamental. (p.147)

As atividades analisadas foram realizadas durante o Estágio I, II e III em escolas da rede pública municipal e estadual da cidade de Manaus, com localização distribuídas em áreas da periferia, do centro e outras áreas mais isoladas da cidade. Em alguns casos (duas escolas) funcionam com o tempo integral e as outras com o período de quatro horas de trabalho diário.

Como professoras da disciplina, acompanhamos os trabalhos realizados ao longo do processo e estudamos o Projeto Político Pedagógico no tocante à proposta do Estágio no referido curso. Os dados foram coletados durante as disciplinas de Estágio I, II e III por meio de discussão com os acadêmicos, tendo como provocações as seguintes questões norteadoras: Quais as inquietações que você tem na realização do estágio? Quais aprendizagens construídas no estágio você considera significativas para a sua formação?

No último período (Estágio III), os alunos responderam a um questionário com perguntas abertas que trouxeram questões acerca das contribuições do estágio para a formação docente, as dificuldades, os pontos mais relevantes do estágio, a vinculação do estágio com uma pesquisa e a elaboração do Trabalho de Conclusão do Curso.

Buscamos enfatizar a formação em uma atitude investigativa por parte do aluno-estagiário, no sentido de ele, no desenvolvimento do estágio, poder identificar os problemas de ensino-aprendizagem, construindo propostas a partir da literatura educacional e da socialização de experiências com o docente de estágio e com os demais discentes-estagiários e, na utilização de diferentes recursos, buscar formas de responder as demandas do cotidiano escolar.

\section{O Estágio Supervisionado no curso de Pedagogia na UEA dentro do Projeto Político Pedagógico}

Conforme o Projeto Político Pedagógico do Curso de Pedagogia da Universidade do Estado do Amazonas, o Estágio Supervisionado do Curso de Licenciatura em Pedagogia atende à Resolução CNE/CP $\mathrm{N}^{\mathrm{o}}$ 1, de 15 de maio de 2006 e compreende uma carga horária de 330 (trezentas) horas distribuídas nos três últimos períodos do curso. O Estágio é concebido como a experiência profissional na qual se busca articular e construir saberes, a partir da prática docente, da participação na gestão de processos educativos e da atividade de pesquisa, em escolas da rede pública e particular de ensino, preferencialmente da Educação Infantil e dos Anos Iniciais do Ensino Fundamental.

A proposta é sustentada pelos pressupostos alicerçados nos estudos de Schön (1992), Zeichner (1992) e Pimenta (1992), os quais tratam da formação do professor reflexivo e pesquisador, como uma etapa de construção/reconstrução de saberes, dos quais o estágio é tido como momento do exercício e experimentação. Desta forma, o estágio proposto também se orienta na concepção de professor reflexivo e pesquisador, o qual, como profissional prático, aprende a partir da análise e interpretação de sua própria atividade. Enfatiza a necessidade de desenvolvimento de capacidades de pesquisa, análise, avaliação, criação de estratégias, práticas e de comunicação. Compreende atividades teórico-práticas 
direcionadas para o exercício profissional da docência, os diferentes processos de gestão e organização do trabalho escolar e o desenvolvimento de pesquisa em contexto educacional.

O estágio do curso de Pedagogia da Universidade do Estado do Amazonas se organiza em três períodos que preveem a inserção dos alunos estagiários em escolas de Educação Infantil e Ensino Fundamental. As ementas de cada etapa do Estágio (I, II e III) propõem atividades que vão se articulando com as diferentes fases da pesquisa para no final culminar com a produção de um relatório destas atividades, ou seja, o Trabalho de Conclusão de Curso. No Estágio I a ementa propõe a docência e a gestão escolar na Educação Infantil e nos Anos Iniciais do Ensino Fundamental para realizarem a observação e o diagnóstico da realidade educacional. Nesta etapa, é realizada a construção do Projeto de Pesquisa na e sobre a prática pedagógica, bem como estudada a concepção teórica do professor reflexivo-pesquisador. Para o Estágio II, a ementa propõe a reflexão e a prática do planejamento do trabalho pedagógico na Educação Infantil e Anos Iniciais do Ensino Fundamental, a partir das teorias do desenvolvimento humano, e a sua realização se representa pela atividade de planejamento e desenvolvimento do plano de ação a partir das problemáticas levantadas, assim como pela análise dos processos de gestão nas escolas de Educação Infantil e Anos Iniciais do Ensino Fundamental. Inicia-se a pesquisa de campo a partir do projeto de pesquisa elaborado. A ementa do Estágio III prevê a reflexão sobre as teorias da gestão educacional e escolar aplicadas às diferentes modalidades e níveis de educação subsidiada pela disciplina de Organização do Trabalho Pedagógico e Gestão Escolar, além da articulação entre a ação educativa e a gestão escolar e a realização do projeto de intervenção (plano de ação docente) subsidiado pela reflexão coletiva e pela pesquisa. É importante salientar que as disciplinas Pesquisa e Prática Pedagógica I e II trabalham conjuntamente com o Estágio subsidiando os estudos e discussões para a elaboração do projeto de pesquisa, sua aplicação e elaboração do TCC que deve apresentar os resultados deste trabalho em forma de monografia. As bancas de defesa são organizadas conjuntamente e delas participam o orientador e mais dois professores que sejam pesquisadores da temática investigada.

Durante esse processo, o docente responsável pela disciplina acompanha e orienta os alunos nas atividades realizadas na escola campo, na elaboração parcial dos relatórios, nas discussões coletivas e orientações individuais, podendo o aluno contar também com a contribuição de um professor orientador para sua pesquisa, de acordo com o tema estudado. Alguns orientadores pertencem a outros cursos, como Letras, Matemática, Ciências Biológicas, dependendo do objeto da pesquisa.

\section{O estágio: aprendizagens e desafios pelo olhar discente}

A partir da discussão do texto sobre os saberes da docência (Pimenta, 2000), os alunos foram indagados sobre como se percebiam no momento do estágio, sobre quais conhecimentos já possuíam e quais consideravam mais relevantes. Destas reflexões ocorreu a produção individual de um texto que se intitulou Formação de Identidade Docente. Vários sentimentos e inquietações foram identificados nesses textos, e, em muitos casos, os alunos apontaram mais de um quesito, dos quais destacamos os seguintes:

- $\quad$ Preocupados com o TCC (23);

- Ansiosos, sem os saberes necessários para dar aula (16); 
- Com muita expectativa para ver a prática da sala de aula (09);

- Tranquilos e com boas expectativas (05);

- Temerosos de não conseguir realizar as atividades (02).

Nos textos alguns revelaram que gostariam de ter mais formação, questionaram a fragilidade da formação recebida até o momento, pois para muitos ainda não tinham aprendido a lidar com alunos, a dar aula, a planejar, a propor alternativas metodológicas para as diferentes situações que já sabiam que encontrariam na sala de aula. No final do Estágio III, 29 alunos responderam a um questionário com perguntas abertas e obtivemos resultados interessantes sobre a articulação estágio/pesquisa. Os 29 alunos responderam que foi muito produtiva. Das respostas dadas por eles, retiramos algumas frases que corroboram essa afirmação:

"[...] é produtiva na medida em que tiramos das situações reais a própria problemática do cotidiano" (aluna M.S.S.)

"[...] a pesquisa nos dá possibilidade de olhar a escola sob várias perspectivas." (aluna A. M.C. O.)

"O projeto de pesquisa nos estimula a ter um olhar mais atento sobre os sujeitos e o contexto da realidade escolar. As leituras necessárias para a construção do trabalho favorece a formação docente." (aluna V. da S.I.)

Essas afirmações vindas de alunos que vivenciaram o estágio vinculado a uma pesquisa nos permitem dizer que essa experiência é positiva e que a concepção de estágio adotada pela Universidade do Estado do Amazonas é algo que favorece a formação desses futuros profissionais da educação, no sentido que lhes possibilita um olhar mais atento e completo sobre a realidade escolar, local onde irão atuar. Ainda nos possibilita afirmar que a vinculação estágio/pesquisa provoca a necessidade de um aprofundamento nas teorias estudadas e oportuniza a sua discussão com outros profissionais, no caso, o orientador. Essa reflexão construída a partir de um projeto de pesquisa desenvolve nos futuros docentes a disposição e a competência para pensar o próprio trabalho, favorecendo a autonomia. (ANDRÉ, 1995).

Um dos pontos observados durante o acompanhamento dos alunos de Estágio estava no conflito entre os objetos de pesquisa identificados nas escolas pelos alunos e os interesses dos professores orientadores e as linhas de pesquisa destes professores. Muitos possuíam interesses de pesquisa distintos dos problemas visualizados na escola, e a tentativa de articular estas duas realidades gerava divergência, ansiedade e dúvidas tanto nos alunos quanto nos professores envolvidos no processo. Pontuamos que estas questões poderiam ser esclarecidas se o currículo do Curso de Pedagogia da Escola Normal Superior fosse mais discutido e refletido junto ao corpo docente para que juntos esclarecêssemos as dúvidas e déssemos os encaminhamentos necessários.

\section{O planejamento, realização e análise do Plano de Ação pelos estagiários.}

Dentre as atividades do Estágio I e II, como já citado nas ementas, está a de realizar um diagnóstico da escola e a partir dele levantar uma problemática a ser estudada para a realização do Trabalho de Conclusão de Curso. Essa problemática é organizada em um projeto de pesquisa que deve ser realizada concomitantemente ao estágio. Uma intervenção a essa problemática é organizada e desenvolvida nos Estágios II e III, nomeada de Plano de Ação. 
O Plano de Ação é um momento importante para o estagiário, pois possibilita um estudo mais aprofundado do trabalho docente. Há elementos nesse propósito que passam despercebidos pelos acadêmicos quando do desenvolvimento das disciplinas. Os estudos para sua realização oportunizam aos alunos estagiários debruçarem-se sobre o trabalho docente no saber fazer e nos saberes do conhecimento para tal fim. Enquanto atividade do estágio pretende possibilitar ao aluno estagiário fazer o exercício da docência e articular os conhecimentos trabalhados durante o curso por meio do seu planejamento e execução. Para eles esse é um dos momentos mais desafiadores do estágio, bem como de aprendizagens significativas e integradoras. Ao final da realização desse trabalho, os professores orientadores da disciplina promovem um encontro de socialização das experiências vivenciadas pelos acadêmicos, e, a partir desses relatos, essas atividades são analisadas e refletidas à luz das teorias estudadas. Os acadêmicos produzem um relatório sobre o estágio no qual descrevem e analisam as atividades desenvolvidas. Dentre os vários pontos levantados pelos estagiários, destacamos o plano de aula, as metodologias utilizadas, os instrumentos de avaliação e a reflexão sobre o trabalho realizado por meio do registro.

\section{O plano de aula}

Esta atividade prevista no estágio deve ser planejada pelos alunos estagiários e precisa estar de acordo com o planejamento dos professores titulares da turma da escola campo. Outro elemento importante é a necessidade de articular a atividade ao tema da pesquisa, a fim de coletar dados para o trabalho final. Segundo Vasconcellos (2000, p.35):

Planejar é antecipar mentalmente uma ação a ser realizada e agir de acordo com o previsto; é buscar fazer algo incrível, essencialmente humano: o real ser comandado pelo ideal.

A definição do autor propõe que o planejamento é algo necessário quando pretendemos alcançar um objetivo ou intervir numa realidade da qual temos conhecimento. A tarefa de planejar não é fácil nem para professores com anos de experiência; para os alunos estagiários torna-se algo ainda mais complexo, uma vez que o plano deve ser o guia da atividade a ser realizada. Aspectos importantes do trabalho pedagógico tornamse concretos para os acadêmicos, como a interdisciplinaridade, e há a identificação do tipo de conteúdo trabalhado para que o plano idealizado seja algo claro, coerente e que possibilite o maior número de aprendizagens aos alunos.

Nesse momento é possível perceber que a compreensão dos estagiários acerca de questões fundamentais não é clara, o que prejudica e retarda o processo de planejamento e realização das aulas. Em vários casos pode-se perceber que encarar o plano como algo real torna-se difícil, pois para muitos deles essa é a primeira experiência como docentes, ou “estar à frente de uma turma”, como dizem nos relatórios finais do trabalho.

Para melhor acompanhar o processo, foi estabelecida uma agenda de atendimento individual no primeiro momento e uma em duplas no segundo momento. Dentre as diversas atividades planejadas, ressaltamos algumas que se destacaram pela forma como foram trabalhadas pelos estagiários, trazendo boa repercussão nas escolas campo:

- Atividades com a história de vida dos alunos por meio da produção de álbuns (II Período - Educação Infantil);

- Discussão sobre o meio ambiente a partir de um jogo de computador elaborado para esse fim ( $\left.1^{\circ} \mathrm{ano}\right)$; 
- Atividades de produção de textos a partir do relato de uma fábula ( $2^{\circ}$ ano);

- Atividades de produção textual (bilhetes) com elementos dos contextos dos alunos ( $3^{\circ}$ ano);

- Catalogação de plantas e construção de um herbário ( $4^{\circ} \mathrm{ano}$ );

- Resolução de problemas matemáticos a partir da comparação de preços de produtos nos panfletos distribuídos por dois supermercados diferentes (5ano);

- Atividades de compra e venda em um mercadinho utilizando dinheiro de brinquedo ( $\left.5^{\circ} \mathrm{ano}\right)$.

Nesse processo, questionamos sobre o aprender a fazer e sobre os saberes pedagógicos presentes no cotidiano dos professores. Os alunos demonstraram algumas dificuldades para trabalhar com metodologias adequadas a cada tipologia de conteúdo, bem como para elaborar instrumentos de avaliação que estivessem de acordo com o plano de aula. Muitas vezes se agarram à ideia de que basta a utilização de recursos inovadores para garantir a aprendizagem dos alunos. Desse modo, o trabalho de orientação torna-se imprescindível para levar o aluno estagiário a perceber que esse é um dos componentes do plano, porém não é o único e que devem se levar em conta os objetivos previstos para a atividade a ser desenvolvida.

A realização das atividades nos permitiu observar a atuação desses estagiários junto aos alunos dos Anos Iniciais do Ensino Fundamental e Educação Infantil. Ao final desse período de atividades realizamos uma socialização de experiências, o que nos permitiu avaliar a atividade no tocante ao planejamento, execução e saberes aprendidos/ apropriados pelos estagiários. Alguns relatos nos dão a dimensão do significado da atividade para eles:
Eu gostei muito .... me senti professora e descobri que é isso que eu quero ser. (aluna R.B. S.)

Descobri que posso fazer diferente... minha experiência era somente na rede particular de ensino, com os alunos da escola pública descobri que tem outras possibilidades de trabalho. (aluna D. F. O.)

O trabalho com textos junto aos alunos me ajudou a perceber como desconhecemos as teorias que amparam nossas práticas de ensino de leitura e escrita (referindo-se a aprendizagem da escrita a partir da apropriação da linguagem). (aluna D. B.F.)

Um item destacado pelos acadêmicos é a necessidade do planejamento. Planejar as atividades permite explorar todas as possibilidades que aquele conteúdo traz para a aprendizagem do aluno, bem como oportuniza aulas mais prazerosas. Ao professor em formação dá segurança para a realização do trabalho. Na fala de uma aluna “ tudo que aprendemos faz sentido. O planejamento é parte imprescindível do trabalho docente" (aluna L.J.S), remetendo-se às aulas da disciplina de Planejamento de Ensino e Avaliação. Essa atividade leva-os a compreenderem que o professor é alguém que elabora planos de atividades, desenvolve metodologias, reproduz e interpreta conteúdos e avalia processos. Assim como os cientistas, ele inventa e implementa ações que produz novos fenômenos cognitivos e põe à prova conhecimentos existentes.

Ver-se como um docente-pesquisador implica não perder a oportunidade de elaborar e formalizar o que ele vai construindo em termos de novos conhecimentos. No caso específico da nossa experiência, elaborar uma pesquisa pedagógica e materializá-la em um TCC exigiu que os estagiários compreendessem que "ser professor" não se reduz a "realizar atividades" de ensinar ou realizar procedimentos burocráticos de "ensinador" 
sem refletir sobre estas atividades. Ser professor é construir e, sobretudo, reconstruir conhecimentos.

\section{As metodologias utilizadas}

Durante o período de observação e diagnóstico, vários registros realizados pelos alunos no diário de campo apontaram a falta de alternativas metodológicas. Esse foi um dos pontos que trouxeram muitas indagações sobre o como fazer. A discussão sobre a intencionalidade do trabalho docente é ainda algo muito voltado simplesmente a uma questão didática, muitas vezes confundida com simples técnicas de trabalho. Ter claro os objetivos que os alunos precisam alcançar ao final de cada aula é um norteador para a escolha das metodologias empregadas, bem como conhecer que tipo de conteúdo está sendo trabalhado. Isso nos remete à dimensão projetiva da didática que viabiliza propor novas formas de ação didática. (AZZI; CALDEIRA, 2006).

Para os acadêmicos, essa ação esteve pautada em metodologias que envolveram a ludicidade por meio de jogos, atividades de contar histórias, música, dramatização, caracterização de personagens, enfim, promovendo uma participação mais efetiva das crianças no trabalho realizado. Esse envolvimento se mostrou aos estagiários como algo significativo uma vez que a resposta dos alunos a essas atividades foi muito positiva, e a avaliação dos resultados quanto aos objetivos alcançados também o foram. Dos registros no relatório final do estágio, destacamos alguns:

"Planejar atividades que envolvam mais os alunos dá mais resultado na aprendizagem." (relatório da aluna D.B. F.)

"Os alunos gostam mais das aulas em que eles participam por meio de jogos e outras dinâmicas... eles aprendem mais e dizem que a aula passa rápido." (relatório do aluno J.A. B. S)

"Planejar essas atividades deu trabalho, mas valeu a pena. Os alunos aprenderam bastante e gostaram muito." (relatório do aluno V. L. C)

\section{Os instrumentos de avaliação}

A avaliação constitui-se como um dos itens do planejamento escolar. De acordo com Hoffman (2003, p.15), “a avaliação é essencial à educação, inerente e indissociável enquanto concebida como problematização, questionamento, reflexão sobre a ação”.

Como um dos componentes do plano, a elaboração de instrumentos de avaliação para as atividades realizadas durante o Plano de Ação desenvolvido pelos estagiários foi outro ponto de questionamentos e reflexões. Conhecer e utilizar diferentes instrumentos de avaliação, elaborando-os de forma coerente com o que foi trabalhado na turma foi considerado um desafio pelos acadêmicos. Ao organizar o plano de aula com todos os seus componentes, os estagiários se deparam com a avaliação como algo que faz parte do processo ensino e aprendizagem e não um momento pontual e alheio a esse processo.

Essa constatação possibilita-lhes a compreensão da avaliação contínua, formativa, processual.

\footnotetext{
"A avaliação realizada no final da aula demonstrou o objetivo alcançado e o que foi só parcialmente alcançado. No resultado dos alunos percebi que poderia ter explicado melhor o assunto."(relatório do aluno L.C.D)

"Quando os alunos começaram a jogar no computador (o exercício de avaliação) ficou claro que eles tinham compreendido bem o tema explorado, porém, percebemos que as frases longas usadas no jogo
} 
dificultaram as respostas dadas por eles, pois muitos ainda têm dificuldades com leitura. Deveríamos ter usado mais figuras. "(relatório da aluna V. J.T.)

Essas reflexões anotadas pelos acadêmicos em seus relatórios nos levam a afirmar que eles compreendem a avaliação como um processo formativo que dá elementos para o professor e para o aluno refletirem sobre seus saberes e atuações. Essas constatações vão sendo tecidas ao longo do processo de realização do estágio e suas atividades. Muitas vezes elas não são percebidas imediatamente, e o registro para posterior leitura e análise é que possibilita esse olhar reflexivo sobre o trabalho docente. O registro, nesse caso, foi outro ponto importante a ser analisado.

\section{A reflexão do trabalho a partir do registro}

O estágio proposto pela Universidade do Estado do Amazonas se orienta na concepção de professor reflexivo e pesquisador, em cuja concepção o professor, enquanto profissional prático, aprende a partir da análise e interpretação de sua própria atividade. Contudo, essa reflexão só é possível a partir da memória que se faz do já vivenciado. Laneve (citado por Pimenta (2008) aponta o registro sistemático das experiências como elemento essencial para construir a teoria do saber didático a partir da prática. Ainda, segundo a mesma autora, essa documentação deve ser sobre

[...] as escolhas feitas pelos docentes (o saber que os professores vão produzindo, as suas práticas), os processos e os resultados. [...] Documentar não apenas as práticas tomadas na sua concreticidade imediata, mas buscar a explicitação das teorias que se praticam, a reflexão sobre os encaminhamentos realizados em termos de resultados conseguidos. (PIMENTA, 2008, p. 60)

No sentido em que aponta a autora, os estagiários utilizam do caderno de campo para fazer seus registros e, especificamente, o plano de ação para posteriormente produzirem o relatório. Essa prática não é algo comumente encontrada nas escolas, haja vista os professores se encontrarem assoberbados pelos trabalhos de preenchimento de relatórios, mapa de notas, pareceres sobre os alunos que acabam não priorizando o registro das próprias atividades, bem como as reflexões que elas lhes provocam.

Para os estagiários, esse momento de retomar "seus escritos" ganha bastante sentido quando analisam os dados coletados nessas atividades para finalizarem o Trabalho de Conclusão de Curso.

Quando indagados sobre as análises que fizeram de suas atividades, se reportam aos registros realizados como uma memória importante do trabalho docente. Isso nos leva a afirmar que esses estagiários vão construindo sua experiência de ser professor a partir das vivências que realizam na escola e, sobretudo, das análises que fazem sobre elas.

Essa experiência é algo que precisa ser consolidada no seio das escolas, uma vez que essa não é uma prática entre os professores. Talvez por isso, necessita ser bem iniciada e vivenciada nos estágios durante a formação inicial a fim de que possa ser amadurecida e incorporada no trabalho pedagógico desses futuros profissionais da educação.

\section{Considerações finais}

Pensar o estágio como espaço/tempo de formação de professores é um desafio que envolve diferentes sujeitos: a instituição 
formadora, os sujeitos do processo (graduandos e professores) e a instituição que recebe os estagiários. O trabalho apresentado demonstra que o estágio é fundamental na formação dos futuros professores, uma real possibilidade de aproximação da teoria com a prática, o que, de certa forma, também nos leva a perceber que a sua organização pode possibilitar ou dificultar as aprendizagens necessárias aos licenciandos. A intencionalidade do trabalho pedagógico realizado em sala de aula possibilita que o processo de ensino e aprendizagem alcance os objetivos propostos. Esse trabalho, por sua vez, exige do professor saberes para uma organização que viabilize sua melhor condução. No percurso das atividades desenvolvidas durante o Estágio Supervisionado pelos acadêmicos, o planejamento destacou-se como um ponto relevante para a formação e para a construção da identidade de professor. Nesse processo aparecem muitas dificuldades que vão da apropriação dos conteúdos das disciplinas às de acompanhamento do professor orientador que, muitas vezes, acaba não conseguindo efetivamente acompanhar todos os trabalhos.

Destacamos também que aprender o saber fazer deve superar o ensino de técnicas e métodos simplesmente. É o momento em que, ao debruçar-se sobre o trabalho docente enquanto prática social, o professor em formação vai refletindo sobre o próprio trabalho, registra o vivenciado e analisa sua ação, de modo que esse momento se constitui não em um simples momento da prática, mas em um espaço importante de formação e construção da identidade profissional.

Percebemos também que não podemos cair no reducionismo e valorizar somente a dimensão procedimental na formação de professores, daí a importância de não se "apegar" de forma demasiada à experiência e valorizar "somente" a formação do professor que "sabe fazer”, mas que não reflete sobre este "fazer"; portanto, precisamos formar o pesquisador no sentido amplo em detrimento da formação didático-pedagógica do docente que resvala somente no saber-fazer sem a reflexão que esta atividade exige.

O estágio vinculado à pesquisa aparece como uma oportunidade de desvelar melhor a realidade escolar, bem como possibilitar um aprofundamento dos estudos, conforme vimos nas falas dos alunos. Assim, podemos afirmar que essa vinculação é algo positivo e proporciona uma formação mais reflexiva da docência, o que leva os alunos a pensarem na construção dessa identidade profissional para eles próprios. Nesse sentido, pensamos como Leite (2011, p.56) que

[...] é preciso considerar um processo formativo no qual o estágio tenha por objetivo formar o docente como um profissional crítico e reflexivo, apto a compreender e atuar na realidade educacional contemporânea, propondo alternativas pedagógicas, por meio de reflexões e discussões oriundas da teoria trabalhada e da prática do estágio realizado.

Não obstante os problemas apresentados como o acúmulo de atividades, a sobrecarga de trabalho e a sugestão de diferente organização da disciplina no currículo, podemos dizer que o estágio é o eixo norteador do curso de Pedagogia da Universidade do Estado do Amazonas, mesmo sabendo que essa afirmação também nos coloca diante de outros desafios.

\section{Referências}

ANDRÉ, M. O papel didático da pesquisa na formação do professor. Texto apresentado na $18^{\text {a }}$ reunião da ANPED, set de 1995. 
AZZI, S. C.; A. M. S. Didática e construção da práxis docente: dimensões projetiva e explicativa. In: ANDRÉ, Marli, E. D. A; OLIVEIRA, Rita, N.S. (Orgs.). Alternativas no ensino de didática. 8. ed. Campinas: Papirus, 2006.

GATTI, B. A.; NUNES, M. R. (Orgs.). Formação de professores para o Ensino Fundamental: instituições formadoras e seus currículos. Relatório de Pesquisa. São Paulo: Fundação Carlos Chagas; Fundação Vítor Civita, 2008.

HOFFMAN, J. M. L. Avaliação: mito e desafio: uma perspectiva construtivista. 32. ed. Porto Alegre: Mediação, 2003.

LEITE, Y. U. F. O lugar das práticas pedagógicas na formação inicial de professores. São Paulo: Cultura Acadêmica. 2011.

PIMENTA, S. G. Para uma re-significação da didática: ciências da educação, pedagogia e didática (uma revisão conceitual e uma síntese provisória). In: PIMENTA, S. G. (Org.). Didática e formação de professores: percursos e perspectivas no Brasil e em Portugal. 5 ed. São Paulo, Cortez, 2008.

Saberes pedagógicos e atividade docente. São Paulo: Cortez, 2000. O estágio na formação de professores: unidade teoria e prática? São Paulo. Cortez. 1992.

PIMENTA, S. G.; GHEDIN, E. (Orgs.). 0 professor reflexivo no Brasil. São Paulo: Cortez, 2002.

PIMENTA, S. G.; LUCENA, M. S. Estágio e docência. 3.ed.São Paulo: Cortez, 2008.

SCHON, D. A. Formar professores como profissionais reflexivos. In: NÓVOA, A. (Coord.). Os professores e a sua formação.
Lisboa: Publicação Dom Quixote/ Instituto de Inovação Educacional, 1992.

UNIVERSIDADE DO ESTADO DO AMAZONAS. Projeto político pedagógico do curso de Pedagogia. 2010.

VASCONCELLOS, C. S. Planejamento: Projeto de ensino-aprendizagem e projeto político-pedagógico. 9. Ed. São Paulo: Libertad Editora, 2000.

ZEICHNER, K. El maestro como professional reflexivo. Cuadernos de Pedagogía. 220, 44-49, 1992. 